T. E. Спасова, К. Н. Дементьева, С. С. Хундоев. Оценка факторов риска кровотечения у больных язвенной болезнью

УДК 616.33-005.1

DOI: 10.18101/2306-1995-2019-2-25-32

\title{
ОЦЕНКА ФАКТОРОВ РИСКА КРОВОТЕЧЕНИЯ У БОЛЬНЫХ ЯЗВЕННОЙ БОЛЕЗНЬЮ
}

\section{(C) Спасова Татьяна Евгеньевна}

кандидат медицинских наук, доцент кафедры поликлинической терапии и профилактической медицины, Бурятский государственный университет им. Д. Банзарова

Россия, 670000, г. Улан-Удэ, ул. Смолина, 24а

E-mail: tspasova@inbox.ru

\author{
(C) Дементьева Кристина Николаевна \\ студентка, \\ Бурятский государственный университет им. Д. Банзарова \\ Россия, 670000, г. Улан-Удэ, ул. Смолина, 24а \\ E-mail: kristallik2097@gmail.com \\ (C) Хундоев Самба Сергеевич \\ студент, \\ Бурятский государственный университет им. Д. Банзарова \\ Россия, 670000, г. Улан-Удэ, ул. Смолина, 24а \\ E-mail: sambik_16@mail.ru
}

Исследовали факторы риска желудочного кровотечения у пациентов, госпитализированных в гастроэнтерологическое отделение Республиканской клинической больницы им. Н. А. Семашко. Проведен анализ 162 историй болезни. Преобладали факторы риска кровотечения: мужской пол, возраст более 55 лет, прием нестероидных противовоспалительных препаратов, длительный язвенный анамнез, воспалительный фон слизистой желудка, наличие инфекции Helicobacter pylori. Размеры язвенных дефектов достоверно больше были у мужчин по сравнению с женщинами в 2,5 раза, у лиц старше 55 лет по сравнению с более молодыми пациентами в 2,8 раза, и у больных, принимавших в анамнезе нестероидные противовоспалительные препараты, в 3,2 раза. Выявлена зависимость локализации язвы в антральном отделе от мужского пола, азиатской национальности, курения, приема нестероидных противовоспалительных препаратов и наличия инфекции Helicobacter pylori.

Ключевые слова. Язвенная болезнь желудка, факторы риска, желудочное кровотечение, инфекция Helicobacter pylori, нестероидные противовоспалительные препараты, курение, мужской пол, антральный отдел.

Для цитирования:

Спасова Т. Е., Дементьева К. Н., Хундоев С. С. Оценка факторов риска кровотечения у больных язвенной болезнью // Вестник Бурятского государственного университета. Медицина и фармация. 2019. Вып. 2. С. 25-32.

Распространенность язвенной болезни среди взрослого населения в настоящее время остается высокой и составляет 7-10\%. По данным Федеральной службы государственной статистики в 2017 г. в Российской Федерации заболеваемость язвенной болезнью желудка и двенадцатиперстной кишки не претерпела существенных изменений с 
2015 г. и была 1244,3 на 100.000 населения, впервые выявленные случаи заболевания составили 122,4 на 100000 населения [4]. В то же время в России и во всем мире отмечается рост случаев осложненного течения язвенной болезни желудка, особенно желудочного кровотечения, преимущественно у лиц пожилого возраста, имеющих полиморбидную патологию. Так, число больных с язвенными кровотечениями увеличилось в нашей стране за 10 лет с 28913 в до 64045 [5]. В целом, частота кровотечений из верхних отделов желудочно-кишечного тракта составляет 30-150 случаев на 100,000 взрослых людей в год, и в большинстве случаев они приводят к госпитализации [3]. 68\% случаев осложненного течения заболевания составляют люди старше 60 лет, а 27\% - в возрасте более 80 лет [10]. Возникновение желудочного кровотечения усугубляет течение сопутствующей патологии, во многих случаев отличается рецидивирующим течением. В группе больных с рецидивирующими кровотечениями показатель летальности остается высоким (до 30\%) [10]. Риск желудочного кровотечения повышается при наличии факторов риска, к которым относят: пожилой возраст, мужской пол, курение, употребление алкоголя, инфекция Helicobacter pylori, сопутствующая патология [9].

Поэтому у пациентов с впервые диагностированной язвенной болезнью, а также с обострением ранее существовавшего заболевания целесообразно диагностировать факторы риска кровотечения для своевременной профилактики осложнения.

Целью исследования явилось изучение факторов риска развития желудочного кровотечения у больных язвенной болезнью желудка, госпитализированных в гастроэнтерологическое отделение Республиканской клинической больницы им. Н. А. Семашко г. УланУдэ.

\section{Материал и методы исследования}

Был проведен ретроспективный анализ 162 историй болезней пациентов, которые находились на лечении в Республиканской клинической больницы им. Н. А. Семашко г. Улан-Удэ в 2016-2018 годах. Оценивали возраст, пол, национальность, социальный статус, сопутствующая патология, курение, прием НПВП и антикоагулянтов, длительность заболевания, частоту обострений, размеры и локализацию язв, наличие осложнений в анамнезе. Изучали зависимость размера и локализации язв от пола, возраста, национальности, курения, приема нестероидных противовоспалительных препаратов, наличия H. pylory. Статистическую обработку данных проводили с использованием критериев Стьюдента и $\mathrm{x}^{2}$ Пирсона. Достоверность результатов принимали при $\mathrm{p} \leqq 0,05$. 
T. E. Спасова, К. Н. Дементьева, С. С. Хундоев. Оценка факторов риска кровотечения у больных язвенной болезнью

\section{Результаты исследования}

В исследовании мужчины составили 58\%, женщины - 42\%, средний возраст $56,3 \pm 0,5$ лет, азиаты составили $35,8 \%$. Из общего количества пролеченных 3 (1,9\%) были учащимися, 69 человек $(42,6 \%)-$ работающими, 23 (14,2\%) человека не работали, 67 (41,4\%) - пенсионеры. 8 человек $(4,9 \%)$ злоупотребляли алкоголем, остальные пациенты отрицали употребление алкоголя. Наличие табакокурения, отметили 60 больных (37\%).

Сопутствующая патология была выявлена у 70 больных (43,2\%). Это заболевания сердечно-сосудистой системы у $25 \%$ больных (ишемическая болезнь сердца, гипертоническая болезнь; другие заболевания желудочно-кишечного тракта у 96,7\% больных; сахарный диабет в $10,4 \%$ случаев. Лечение нестероидными противовоспалительными препаратами (аспирин, диклофенак, вольтарен) в анамнезе получали 98 человек (60\%), причем самостоятельно, без консультации со специалистами - 10\%. По поводу сопутствующей сердечно-сосудистой патологии $30 \%$ больных принимали гипотензивные препараты и антикоагулянты.

Впервые выявленная язвенная болезнь составила $43,6 \%$ случаев. У больных с ранее диагностированным заболеванием редкие обострения наблюдались у 30 человек $(33,7 \%)$, а частые, более 1 раза в год у 15 людей $(16,9 \%)$, впервые обострение выявилось у 48,3\% пациентов. Кровотечение в анамнезе отметили 11,2 \% больных. Локализация язвенного дефекта в антральном отделе наблюдалась у 63 человек $(38,9 \%)$, в теле желудка - у 33 (20,4 \%), в кардиальном отделе - у $12(7,4 \%)$, в двенадцатиперстной кишке - у 54 человек (33,3\%). Чаще всего язвы развивались на фоне катарально-эрозивного, катарально-атрофического и эрозивно-геморрагического гастрита. Средний размер язвы $(0,5-1 \mathrm{~cm})$ преобладал у 77 человек $(48,4 \%)$, но также часто встречались большие язвы (1,1-2,9 см) у 38 больных $(23,9 \%)$, гигантские язвы (>3 см) у 4 человек $(2,5 \%)$, которые страдали язвенной болезнью более 10 лет. Чаще наблюдались одиночные язвы (в 84,5\% случаев).

Инфекция Helicobacter pylori диагностирована в 68\% случаев. Все пациенты прошли курс эрадикационной тройной терапии с кларитромицином. Доказано, что своевременная эрадикация Helicobacter pylori предупреждает развитие кровотечений, в отсутствии лечения рецидивы кровотечений возникают в $30 \%$ случаев и более [7].

Известно, что у мужчин распространенность язвенной болезни выше, чем у женщин. Причем это в большей степени выражено при локализации язвы в двенадцатиперстной кишке. При локализации язвы в желудке половые различия несколько сглаживаются $[1,8]$.

Как видно из таблицы 1, в исследовании установлено, что размеры язвенных дефектов достоверно больше были у мужчин по сравнению с женщинами в 2,5 раза, у лиц старше 55 лет по сравнению с более 
молодыми пациентами в 2,8 раза, и у больных, принимавших в анамнезе нестероидные противовоспалительные препараты, в 3,2 раза.

Половые гормоны оказывают выраженное влияние на обменные процессы в организме, в том числе на процессы регенерации, клеточной дифференцировке клеток слизистой желудка. В экспериментах доказано, что фолликулин тормозит развитие язвы слизистой желудка, в то время как мужской половой гормон провоцирует и форсирует их образование [5]. При курсовом применении эстрогенов несколько тормозится кислотовыделительная и пепсинообразующая функция желудка.

В патогенезе язвенной болезни у лиц пожилого и старческого возраста возрастает роль факторов, способствующих ослаблению защитных свойств слизистой оболочки гастродуоденальной зоны. Значение этих факторов (в первую очередь, атеросклеротических изменений сосудов желудка, снижающих трофику его слизистой оболочки) становится особенно заметным в тех случаях, когда заболевание возникает без участия Helicobacter pylori (y 20-30\% больных с язвами желудка) [6].

Ульцерогенное влияние нестероидных противовоспалительных препаратов неоспоримо доказано. Первый механизм развития язв связан с непосредственным повреждением слизистой оболочки во время всасывания нестероидных противовоспалительных препаратов. Второй механизм обусловлен ингибированием циклооксигеназы ключевого фермента в каскаде метаболизма арахидоновой кислоты, которая является предшественником простагландинов, простациклинов и тромбоксанов. Ингибирование конститутивной изоформы циклооксигеназы-1 создает дефицит простациклина I2, ухудшая кровоток в стенке желудка, а снижение синтеза простагландина Е2 ведет к уменьшению секреции бикарбонатов и слизи, повышению кислотопродукции, что усиливает дисбаланс факторов защиты и агрессии и способствует ульцерогенезу. Развитие неблагоприятных эффектов на фоне длительного приема нестероидных противовоспалительных препаратов, отмечается во всех отделах желудочно-кишечного тракта, но чаще всего выражена прежде всего в антральном отделе желудка, где более высокая плотность рецепторов простагландинов [2].

Язвы антрального отдела чаще, чем язвы других локализаций осложняются кровотечением и малигнизацией. Связано это с колонизацией слизистой антрального отдела Helicobacter pylori, которая снижает защитные свойства слизистой, повышает продукцию соляной кислоты, пепсина, вызывает полморфноклеточную инфильтрацию, свободнорадикальное окисление липидов, нарушает микроциркуляцию в слизистой и значимо нарушает процессы регенерации эпителия. Кроме этого, антральный отдел поражается часто рефлюктатом из 
T. E. Спасова, К. Н. Дементьева, С. С. Хундоев. Оценка факторов риска кровотечения у больных язвенной болезнью

двенадцатиперстной кишки, который содержит агрессивные желчные кислоты и компоненты панкреатического секрета.

В исследовании установлено (табл. 2), что достоверно чаще локализация язвы в антральном отделе наблюдается у мужчин, азиатов, курящих, лиц, принимавших нестероидные противовоспалительные препараты и инфицированных Helicobacter pylori.

Таблийа 1

Зависимость размера язвы от наличия факторов риска

\begin{tabular}{|c|c|c|c|c|c|}
\hline Группы & $\begin{array}{c}\text { Мужчины, } 94 \\
\text { чел. }\end{array}$ & $\begin{array}{c}\text { Женщины, } 68 \\
\text { чел. }\end{array}$ & $\mathrm{T}_{\text {крит }}$ & $\mathrm{T}_{\text {эмп. }}$ & $\mathrm{P}$ \\
\hline $\begin{array}{l}\text { Размер } \\
\text { язвы, см }\end{array}$ & $1,8 \pm 0,076 *$ & $0,7 \pm 0,058$ & 1,974 . & 3 & 0,005 \\
\hline Группы & $\begin{array}{l}\text { Старше } 55 \\
\text { лет, } 83 \text { чел. }\end{array}$ & $\begin{array}{l}\text { Младше } 55 \\
\text { лет, } 79 \text { чел. }\end{array}$ & $\mathrm{T}_{\text {крит }}$ & $\mathrm{T}_{\text {эмп. }}$ & $\mathrm{P}$ \\
\hline $\begin{array}{l}\text { Размер } \\
\text { язвы, см }\end{array}$ & $2,8 \pm 0,08^{*}$ & $1,0 \pm 0,05$ & 1,974 & 4,8 & 0,005 \\
\hline Группы & $\begin{array}{l}\text { Принимали } \\
\text { НПВП, } 98 \\
\text { чел. }\end{array}$ & $\begin{array}{l}\text { Не } \\
\text { принимали } \\
\text { НПВП, } 64 \\
\text { чел. } \\
\end{array}$ & $\mathrm{T}_{\text {крит }}$ & $\mathrm{T}_{\text {эмп. }}$ & $\mathrm{P}$ \\
\hline $\begin{array}{l}\text { Размер } \\
\text { язвы, см }\end{array}$ & $2,9 \pm 0,07^{*}$ & $0,9 \pm 0,05$ & 1,974 & 5,57 & 0,005 \\
\hline Группы & $\begin{array}{ll}\text { Азиаты, } & 58 \\
\text { чел. } & \\
\end{array}$ & $\begin{array}{l}\text { He азиаты, } \\
104 \text { чел. }\end{array}$ & $\mathrm{T}_{\text {крит }}$ & $\mathrm{T}_{\text {эмп. }}$ & $P$ \\
\hline $\begin{array}{l}\text { Размер } \\
\text { язвы, см }\end{array}$ & $0,9 \pm 0,08$ & $1,2 \pm 0,07$ & 1,974 & 1,26 & 0,5 \\
\hline Группы & Курят, 60 чел & $\begin{array}{l}\text { Не курят, } 102 \\
\text { чел }\end{array}$ & $\mathrm{T}_{\text {крит }}$ & $\mathrm{T}_{\text {эмп. }}$ & $P$ \\
\hline $\begin{array}{l}\text { Размер } \\
\text { язвы, см }\end{array}$ & $1,2 \pm 0,01$ & $0,9 \pm 0,045$ & 1,974 & 0,77 & 0,5 \\
\hline Группы & $\begin{array}{l}\text { H.pylori } \quad(+), \\
110 \text { чел }\end{array}$ & $\begin{array}{l}\text { H.pylori (-), } \\
52 \text { чел. }\end{array}$ & $\mathrm{T}_{\text {крит }}$ & $\mathrm{T}_{\text {эмп. }}$ & $\mathrm{P}$ \\
\hline $\begin{array}{l}\text { Размер } \\
\text { язвы, см }\end{array}$ & $0,7 \pm 0,1$ & $0,7 \pm 0,1$ & 1,974 & 0,879 & 0,5 \\
\hline
\end{tabular}

Примечание: * различия достоверны при $\mathrm{P} \leq 0,05$; НПВП - нестероидные противовоспалительные препараты; H.pylori - Helicobacter pylori. 
Локализация язвы в зависимости от факторов риска

\begin{tabular}{|c|c|c|c|c|}
\hline & $\begin{array}{c}\text { Антральный } \\
\text { отдел }\end{array}$ & $\begin{array}{c}\text { Другие } \\
\text { локализации }\end{array}$ & Всего & $\chi^{2}$ \\
\hline Мужчины & $43 *$ & 51 & 94 & \multirow{3}{*}{$\begin{array}{c}4.578 \\
(3.841)\end{array}$} \\
\hline Женщины & 20 & 48 & 68 & \\
\hline Всего & 63 & 99 & 162 & \\
\hline Старше 55 лет & 31 & 52 & 83 & \multirow{3}{*}{$\begin{array}{c}0,167 \\
(3.841)\end{array}$} \\
\hline Младше 55 лет & 32 & 47 & 79 & \\
\hline Всего & 63 & 99 & 162 & \\
\hline Азиаты & $31 *$ & 27 & 58 & \multirow[t]{3}{*}{$8,059(3.841)$} \\
\hline Европейцы & 32 & 72 & 104 & \\
\hline Всего & 63 & 99 & 162 & \\
\hline Курят & $48 *$ & 12 & 60 & \multirow[t]{3}{*}{$67,82(3.841)$} \\
\hline Не курят & 15 & 87 & 102 & \\
\hline Всего & 63 & 99 & 162 & \\
\hline $\begin{array}{l}\text { Принимают } \\
\text { НПВП }\end{array}$ & $54 *$ & 44 & 98 & \multirow[t]{3}{*}{$26,37(3.841)$} \\
\hline $\begin{array}{l}\text { Не принимают } \\
\text { НПВП }\end{array}$ & 9 & 55 & 64 & \\
\hline Всего & 63 & 99 & 162 & \\
\hline H.pylori (+) & $20 *$ & 90 & 110 & \multirow[t]{3}{*}{$2,035(3.841)$} \\
\hline H.pylori (-) & 43 & 9 & 52 & \\
\hline Всего & 63 & 99 & 162 & \\
\hline
\end{tabular}

Примечание: * - различия достоверны при $\mathrm{P} \leq 0,05 ;$ НПВП нестероидные противовоспалительные препараты, H.pylori - Helicobacter pylori.

\section{Таким образом:}

1. Среди госпитализированных больных с язвенной болезнью преобладали мужчины, пациенты в возрасте более 55 лет, европейской национальности, работоспособного и старческого возраста, принимавшие нестероидные противовоспалительные препараты, с 
T. E. Спасова, К. Н. Дементьева, С. С. Хундоев. Оценка факторов риска кровотечения у больных язвенной болезнью

длительным язвенным анамнезом, локализацией язвы в антральном отделе желудка и в двенадцатиперстной кишке, смешанным состоянием слизистой оболочки желудка, наличием Helicobacter pylori.

2. Отмечалась высокая частота таких факторов риска кровотечения как курение, возраст старше 55 лет, сопутствующая патология (ишемическая болезнь сердца, гипертоническая болезнь, сахарный диабет), инфекция Helicobacter pylori.

3. Размеры язвенных дефектов достоверно больше были у мужчин по сравнению с женщинами, у лиц старше 55 лет по сравнению с более молодыми пациентами, и у больных, принимавших в анамнезе нестероидные противовоспалительные препараты.

4. Достоверно чаще локализация язвы в антральном отделе наблюдалась у мужчин, азиатов, курящих, лиц, принимавших нестероидные противовоспалительные препараты и инфицированных Helicobacter pylori.

\section{Литература}

1. Афендулов С. А., Журавлев Г. Ю. Тактика ведения больных с состоявшимся кровотечением из пилородуоденальной язвы // ХІ съезд хирургов Российской Федерации, 25-27 мая 2011 г.: материалы съезда. Волгоград: Изд-во ВолгМУ, 2011. С. 646-647.

2. Василенко В. Х., Гребенев А. Л., Шептулин А. А. Язвенная болезнь. М.: Медицина, 1987. 288 с.

3. Гостищев В. К., Евсеев М. А. Гастродуоденальные кровотечения язвенной этиологии. М.: ГЭОТАР-Медиа, 2008. 384 с.

4. Здравоохранение в России. 2017: стат. сб. / под ред. Г. К. Оксенойт // Росстат. М., 2017. 170 с.

5. Ивашкин В. Т., Шептулин А. А. Болезни пищевода, желудка и кишечника / М.: МЕДпресс-информ, 2009. С. 78-83.

6. Ивашкин В. Т., Шептулин А. А. Язвенная болезнь желудка и двенадцатиперстной кишки у лиц пожилого и старческого возраста // Русский медицинский журнал. 1999. № 16. С. 769.

7. Маев И. В., Самсонов А. А., Андреев Д. Н. Желудочно-кишечные кровотечения: клиника, диагностика и лечение // Фарматека. 2014. Т. 2. С. 4753.

8. Минушкин О. Н. Кровотечение из верхних отделов желудочнокишечного тракта: некоторые вопросы тактики и стратегии ведения больных / Consilium Medicum. № 11. 2001.

9. Хакимова Д. Р. Часторецидивирующие язвы двенадцатиперстной кишки: факторы, способствующие формированию, и тактика лечения: автореф. дис. ... канд. мед. наук. М., 2004. 52 с.

10. Barkun A., Sabbah S., Enns R. The Canadian Registry on Nonvariceal Upper Gastrointestinal Bleeding and Endoscopy (RUGBE): Endoscopic hemostasis and proton pump inhibition are associated with improved outcomes in a real-life setting // Am J Gastroenterol. 2004. N 99(7). P. 1238-1246. 


\section{ASSESSMENT OF RISK FACTORS OF STOMACH BLEEDING} IN PATIENTS WITH ULCER DISEASE

\section{Tatiana E. Spasova}

Candidate of Medical Sciences, Associate Professor of the Department of Outpatient Therapy and Preventive Medicine with a course in Health and Safety, Medical Institute, Dorzhi Banzarov Buryat State University 36a, Oktyabrskayast, Ulan-Ude, 670001, Russia E-mail: tspasova@inbox.ru

\section{Kristina N. Dementieva}

\section{Student,}

Medical Institute, Dorzhi Banzarov Buryat State University

36a, Oktyabrskayast, Ulan-Ude, 670001, Russia

E-mail: kristallik2097@gmail.com

\section{Samba S. Hundoev}

\section{Student,}

Medical Institute, Dorzhi Banzarov Buryat State University 36a, Oktyabrskayast, Ulan-Ude, 670001, Russia

E-mail: sambik_16@mail.ru

Risk factors of stomach bleeding in patients admitted to the gastroenterology Department of the Republican clinical hospital were investigated. The analysis of 162 medical records was carried out. Risk factors for bleeding prevailed: male sex, age over 55 years, administration of nonsteroidal antiinflammatory drugs, long-term ulcerative history, inflammatory background of stomach mucosa, presence of Helicobacter pylori infection. The dimensions of ulcerative defects were significantly larger in men compared to women by 2.5 times, in persons older than 55 years compared to younger patients by 2.8 times, and in patients who took a history of nonsteroidal anti-inflammatory drugs by 3.2 times. The dependence of the localization of ulcers in the antrum on male, Asian nationality, Smoking, taking nonsteroidal anti-inflammatory drugs and the presence of Helicobacter pylori infection was revealed.

Keywords: Stomach ulcer, risk factors, stomachc bleeding, Helicobacter pylori infection, nonsteroidal anti-inflammatory drugs, Smoking, male, antrum. 